\title{
Situational Analysis of Indian Furniture Industry
}

\author{
Dr. Neeraj Kumari \\ Associate Professor, Dept. of Management, \\ Faculty of Engineering and Technology, \\ Manav Rachna International Institute of Research and Studies \\ Faridabad, India \\ E-mail: neerajnarwat@gmail.com
}

Received: October 11, 2019 Accepted: November 4, 2019 Published: November 6, 2019

doi:10.5296/jad.v5i3.15607 URL: https://doi.org/10.5296/jad.v5i3.15607

\begin{abstract}
Purpose: The study aims to do marketing mix of plastic furniture industry, to do SWOT analysis of furniture industry and Nilkamal group of companies, and to recommend marketing strategies for the plastic furniture industry.

Research Design, Data \& Methodology: A structured questionnaire has been used to collect primary data. Convenience sampling has been used in the study. The sample size is 120 .

Results: The strengths of Nilkamal are as follows: National leader, Pro-actively enters new segments and markets, Partners well-established companies, Strong distribution in the company, Vast product range with emphasis on quality, Financially strong, and Strong R \& D.

Conclusion: In order to improve its marketing strategies, Nilkamal can take the following steps: Target Kid's furniture kit, Advertise the products as being designed with respect to safety by avoiding sharp edges, The furniture set can be customized to suit the kid's tastes, A retail chain for plastic furniture can be opened in the major cities, A resale store can be opened at major cities in the country where the sales of plastic furniture are high, and Venture into wood-plastic composite furniture.
\end{abstract}

Keywords: marketing mix, plastic, advertising, wood, marketing 


\section{Macrothink}

\section{Introduction}

Furniture industry, each one of the associations and activities drew in with the blueprint, make, movement, and offer valuable and delightful objects of family adaptations. The bleeding edge creates furniture and is an imperative expansive scale fabricating industry in Europe, the United States, and other regions. It is, all things considered, a twentieth century industry, its change having expected the improvement of a mass buyer publicize and the progression of the substantial scale fabricating technique. Earlier furniture making was a craftsmanship, retreating to the most out of date community foundations.

\section{Changing trends in furniture industry}

Some of the reasons for the increasing changes in the furniture industry are:

1) Increasing acquiring energy of Indian shoppers:

a.India is positioned as fourth biggest economy after USA, China and Japan in PPP (Purchasing Power Parity).

b. India is seventh most alluring goal for Foreign Direct Investment (FDI) after US, China, Brazil, UK, Mexico, and Germany.

2) Cheap imports from China: With globalization and World Trade Organization (WTO) directions modest imports from China is influencing Indian furniture industry. The Indian makers have begun making restorative strides like:

a.Upgrading the outlines

b. Using Medium-density fibreboard (MDF) and Molecule sheets

c.Increasing development of composed division

d. Organized retailing

3) Government directions: Expanding limitations on de-forestation and prohibition on dirtying ventures like saw clean and so on is changing the flow of furniture industry.

4) Furniture made of Plastics is one of the quickest developing sub-sections of furniture industry.

5) Demography: Expanding number of core families has been a noteworthy development driver of furniture industry.

6) Infrastructural improvement: Expanding advancement in this has prompt expanding requirement for outfitting. Individuals now need to possess a house and put stock in outfitting it as indicated by their tastes.

7) Change in buyer tastes:

a.Majority of India's populace is beneath the age gathering of 35 years. Their tastes and decision is unique. In has changed the flow and individuals now offer inclination to shading and accommodation. 
b.Plastics Furniture would take a sizable lump of furniture industry due to previously mentioned factors.

\section{Review of Literature}

Jaworski (2018) The study addresses following issues: (1) the 'promising' resources that the train has in play; (2) the slide towards scholarly unimportance and, in this manner, the 'issue'; (3) Chase's perceptions on how the slide may be turned around; and (4) my perspective on what should be possible to invert the slide.

Voorveld et al. (2018) The study examined how shoppers' commitment with social media stages drives commitment with publicizing installed in these stages. The discoveries demonstrate that commitment is exceedingly setting particular; it includes different kinds of encounters on every social media stage with the end goal that each is knowledgeable about a special way. It is additionally demonstrated that commitment with social media promoting itself is entered in clarifying how social media commitment is identified with publicizing assessments. It concluded that there is no such thing as "social media."

Olson et al. (2018) Attributes of the marketing association and their association with technique usage have been the focal point of significant research in the course of recent decades. These qualities incorporate the marketing association's structure, culture, procedures, impact and initiative, among others. In any case, little consideration has been paid to human asset administration arrangements for marketing work force. These approaches, when legitimately actualized, are among the most grounded sparks for suitable individual and authoritative conduct. Firms whose business and marketing methodologies adjust (Fit) exhibited fundamentally more grounded general firm execution scores than those whose business and marketing procedures don't adjust (Misfit).

Dawes (2018) The Ansoff Matrix has been broadly instructed as a component of business training for more than 50 years. It depicts development alternatives as a 2 x 2 matrix of choices, with one pivot speaking to items (existing/new) and the speaking to business sectors (existing/new). Two sensible issues emerge from the matrix. The two issues identify with suspicions or translations relating to newness. On the off chance that one accepts a new item truly is new to the firm, much of the time a new item will at the same time bring the firm into a new, new market. All things considered, one of the Ansoff quadrants, specifically broadening, is excess. On the other hand, if a new item does not really bring the firm into a new market, at that point the mix of new items into new markets does not generally liken to broadening, in the feeling of wandering into a totally obscure business - which the model, and numerous ensuing elucidations of the model in course readings, expects.

Wiley (2017) The examination centers around a smart telephone based AR usage model where clients can see their real surroundings on their smart telephone show, saw through the smart telephones' camera, whereupon virtual substance is overlaid, enlarging the surroundings saw on the show. This innovation isn't yet generally executed for publicizing or marking and openings exist for a retail organization to be the first in its market to actualize it. No such AR encounters are yet executed inside the top of the line furniture market; in this 
manner, an AR involvement in this market would enable such organization to emerge from its rivals.

Chattopadhyay \& Jain (2017) In spite of the fact that the outcome recommends that the sloppy retail segment involves $80 \%-85 \%$ of the aggregate retail pie, they are as yet frightened of the minority of the composed retail segment, which is contained around $15 \%-20 \%$. The Point of differentiation (POD) remains the general administration and the experience that the kirana stores couldn't offer to make advancement in buyer mind which has made by the composed area and subsequently the business wheel of kirana stores are getting slower and slower.

Singh \& Balivada (2017) The market or the purchasers are constantly changing the way they shop. Purchasing at the sorted out retail is a pleasant ordeal for purchasers. The shopping centers are ending up Family Stimulation centers. Some are alluring clients with slogans like "Shop, Eat and Celebrate". Shopping centers with various cineplexes are presently rising which are called as "Hybrid centers". Sorted out retailing in India represents under two percent of the aggregate retailing market. However with forceful ventures, sorted out retailing is set for extension. The Indian government is additionally prone to spend USD 150 billion throughout the following couple of years to create world class foundation, in this way, supporting development in the retail division. A typical component of the development designs of various players seems, by all accounts, to be the hypermarket. All driving Indian retail players are either effectively present or have plans for Hypermarkets.

Chen et al. (2016) With the blend of present day furniture plan and Hui-style architecture, the Normal for particular architecture social components have been brought into the furniture outline in parts of shaping, surface, and development. The smooth and adaptable plan are introduced through Hui-style corbie-step type sofa backrest and the carved window with Jiangnan style, which can be viewed as the synopsis of the advancement outline of Chinese customary furniture and the demand of the time.

Gedenk et al. (2010) Deals advancements have a critical part in the promoting projects of retailers. An extensive level of retailer deals is made on advancement. Likewise, retailer advancements address buyers at the point of offer. In this manner, while advertising in exemplary media is ending up less successful, correspondence through advancements achieves the purchaser at the place and time where most purchase choices are made. The Point of Purchase Advertising Institute (POPAI) finds in an examination from 1999 that the in-store choice rate of customers in Germany, for instance, is $55 \%$, implying that the greater part of all purchase choices are made in stores, instead of before the shopping trip.

\section{Research Methodology}

\subsection{Objectives}

- To do marketing mix of plastic furniture industry.

- To do SWOT analysis of furniture industry and Nilkamal group of companies.

- To recommend marketing strategies for the plastic furniture industry. 


\section{Macrothink}

\subsection{Research Design}

Information has been gathered from both primary and secondary sources. Primary data was collected through a structured questionnaire filled up by the respondents. Secondary data sources include websites, journals, and research papers.

\subsection{Sample Design}

Convenience Sampling was carried out for the study. The sample consisted of customers who had bought products from the furniture industry. The sample size is 120 .

\section{Marketing Mix of Nilkamal}

The marketing mix strategy for the plastic furniture industry can be understood by analyzing two of the major players in the industry, i.e., Nilkamal Plastics, and Supreme Industries. These two companies together form around $50 \%$ of the organized sector in the plastic furniture industry, and hence the behaviour of the industry can be understood by these two firms' functioning.

The 4 Ps consist of Product, Place, Price and Promotion.

1. Product

- Product variety: Nilkamal Plastics has a wide variety of products, forming a wide range. It offers monoblock chairs (its major product), racks, baby chairs, desks, tables, planters and some other forms of almirahs. Supreme plastics too have almost a similar range of products, and hence both offer a wide product variety. Moreover, both of these companies have a wide degree of differentiation in these product ranges as well. For example, Nilkamal's products are CHR2005, CHR2012, and so on. A total of 70 or so chair designs are available. Hence customers have a wide variety to choose from.

- Quality: Both Supreme and Nilkamal maintain good quality standards. They are both ISO certified, and cater to a high level of customer base.

- Design: Both Nilkamal and Supreme have R\&D departments, that maintain a constant outflow of new designs as and when required. Hence design is not a problem with these companies.

- Features: Plastic furniture provides comfort and durability at a cheap price as compared to wooden furniture market.

- Brand name: Nilkamal has a well established brand image, and the brand name has been further enhanced by opening of @home stores. @home has outlets in 17 cities, and it has been able to reach into the minds of customers throughout the nation.

- Sizes: Nilkamal has a production capacity of 48730 metric tonnes p.a., and it manufactures a total of 300 metric tonnes presently. Hence, it already has a huge capacity to expand. Most furniture companies in the plastic segment have a huge capacity plant with them, because it is forecasted that in the future, plastic furniture 


\section{Macrothink

will take over the wooden furniture market. Nilkamal is also expanding its market with@home and retail marketing.

- Returns: The returns of Nilakamal Plastics was 58 crores (NPAT) last year.

Supreme's returns last year were around 35 crores. The sales were of the order of 500 crores last year, and the furniture industry contributed a total of $30 \%$ of the total revenues.

\section{Place}

Nilkamal and Supreme both are manufacturers, and not wholesalers. Nilkamal has now also ventured into the retail furnishing sector with the opening of its @ home stores in 17 different locations across India. It has outlets in Chennai, Hyderabad, Delhi, Ghaziabad, Faridabad, Pune, Nasik and Mumbai. There are about 800 main distributors for its furniture distribution, which are further distributed to more than 1500 outlets across the country.

Nilkamal Plastics first established its markets in the southern part of India. Over there, it was able to establish a great demand for its brand, and was able to establish a good brand image for its product. Nilkamal also has plans to expand its market in the future, to reach out to even more cities.

The area of concern is to discover new avenues of distributions other than the conventional distribution channels as have been adopted by the company. As consumer preference is shifting, their buying behavior is also changing. The consumers in urban and sub-urban markets prefer to buy from retail malls.

\section{Price}

The company faces competition from organized players such as Supreme Industries and unorganized local players. At the retail level, the price of the furniture made by the unorganized segment is lower by 10-15 per cent compared to Nilkamal. To counter this, the company has forged outsourcing relationships with several small manufacturers to widen its geographical reach, increase its volumes and cut down freight cost.

In the organized sector, Nilkamal is $5-10 \%$ higher priced than its main competitor Supreme. In fact this strategy gives it an additional edge in the market and it is perceived as a high quality product.

The price of key raw materials polypropylene and polyethylene determines the company's profitability. It is governed by international price trends and is a factor of crude price movements. The demand primarily comes from the middle and low-income households and is generally sensitive to the price. Considering the steady increase in the income levels and strong brand equity, Nlkamal enjoys to have stable demand in this sector even though it has higher prices.

\section{Promotion}

Nilkamal is extremely strong in promotion activities and the major approach of the company is promotion through BTL (below the line) activities. Of late it has reduced its ATL (above 
the line) activities. The focus is more on the people to people contact. Initiatives such as @ homes are in this direction. Trained personnel look after customer and give them important facts about the product.

Business 2 Business (B2B)

Nilkamal have wide range of product line, they also differentiate their product according to industries, but still industries are not fully aware about their product.

The recommendations for the company are:

- Promotional activities can still be increased in order to strengthen the information and persuasion channels.

- Catalogs at cost effective rates can be provided to the industrial consumers in order to increase the awareness of the various products. Products targeting on small industries can be developed by adopting cost cutting strategies.

As Nilkamal has full plans of expansion for its other major department, i.e., the plastic furniture business, it can plan to bag business to business deals in this sector as well. Offices, educational institutions, committees, and other similar organizations have a large requirement for plastic chairs. The institutional market, consisting of schools, colleges and university hostels, hospitals and nursing homes can be a major market for Nilkamal's plastic furniture.

Listed below are some of the possibilities for Nilkamal to venture.

Nilkamal has monoblock chairs as one of its major products, and has a total of 60 variants under this. Hence it can foray into bulk deals market catering to large organizations, as these chairs can be in huge demand there. This area can hence be of huge potential in the future. There can be companies that do not encourage wooden or metallic furniture, due to various reasons, and Nilkamal can recognize the opportunity in such cases. And gain an upper hand.

Nilkamal also manufactures children's chairs and tables, and it can cater to kid schools and crèches too. In the future, wood furniture is bound to suffer a major barrier, due to environment protection actions being promoted. In such a case, Nilkamal with its well established plastic furniture offerings can gain an upper hand in the market.

It has also entered into the automobile industry recently, and it is felt that there is a huge scope in the future there as well. This is because it can now deal with the hoard of large automobile companies that have entered the Indian market.

Another area that NPL plans to enter is the exercise machine area, where it can plan for a B2B with major gyms across the world.

Considering the fact that wooden furniture may soon be out of contention due to the environmental concern, one of NPL's product, its rack range can do business with offices and libraries across the world.

Hence it is concluded that as plastic may take the position of wooden furniture market in the near future, Nilkamal's well-established and profit generating business can stand a good 


\section{Macrothink}

chance in all the sectors currently occupied by the wooden furniture sector.

In particular, Nilkamal should aim towards specific investments, i.e., the expenditures tailored to a particular company and value chain partner. This will help them grow profits and achieve their positioning in the business market. It is essential that they overcome the competitor challenge, especially the price challenge of smaller players.

They have made a Joint Venture with BITO Lagertechnik Bittmann GmbH, Germany for manufacturing storage systems in metal in India. The joint venture also solves the problem of procuring raw material, a major portion of which Nilkamal now obtains from Lagertechnik, a leading materials handling company in Europe. NPL should use this as an opportunity to enter the Europe market as well, and be the first Indian furniture company to establish a global name. The main POP for Nilkamal is that the cost of production is much lesser as compared to metal and wood industries, with its raw material, i.e. plastic available easily. Hence the profit margins are huge.

\section{SWOT/Situational Analysis of the Indian Furniture Industry}

Strengths

-Politically and financially dynamic locale with stable essentials of state and society and built up advertise economy.

-India is opened to collaboration with all nations.

-Relatively better furniture.

- Relatively low working overhead, particularly work costs.

-High effectiveness in assembling precisely indicated kinds of items.

-Flexibility of neighborhood makers as far as item assortment and conveyances.

Weaknesses

-Limited access to capital and speculations expected to fund new undertakings.

•Predominance of low esteem included items in modern yield and fares.

-Absence of mature market.

-Absence of advanced technologies in this sector.

Opportunities

-Subcontracting and venture openings:

- Foreign organizations can enhance aggressiveness of their items, using key favorable circumstances of Indian market: involvement, low expenses and very much created foundation.

O Development of supply/creation chain from cost focused areas (Eg: China) (long haul point of view). 
-Supply of shopper and modern products:

○ Developing economy builds the interest for semi-prepared modern products. As of now, potential outcomes of nearby industry to fulfill such needs are somewhat constrained.

Threats

- Emerging industry bunches and gatherings.

- Increasing rivalry from neighboring nations.

- Limited potential outcomes for expansive organizations to contend on an equivalent premise with vast number of nearby players.

\section{SWOT/Situational Analysis of Nilkamal Group of Companies}

Nilkamal Ltd. is considered to be the key player in this field. NILKAMAL GROUP OF COMPANIES, with a turnover of over Rs. 500 crores/ USD 125 million is the world leader in the field of plastic moulded furniture and India's number one in the Material Handling plastic crates industry.

It was in 1990 that Nilkamal started the manufacture of moulded furniture.

Following is the SWOT analysis of Nilkamal so as to ascertain where exactly Nilkamal stands and what loop holes might exist.

It is a financially strong group and is diversified in various Plastics divisions. The major strengths of the company are:

- National Leader; Nilkamal is the national leader and dominates the market.

- Pro-Active approach; market Saver Company and reacts to market needs immediately.

- Strong distribution in the country.

- Best product range - uniform presence in all segments i.e. economy, regular and premium range.

- Financially strong.

- Vision for future; the company has a future vision and works on a global mind set.

- $\quad$ Strong in Below the Line (BTL) activities.

- Strong brand equity.

- 17 manufacturing plants in India.

- $\quad$ Strong Research and Development (R\&D) department.

The major weaknesses of Nilkamal are:

- High prices; Nilkamal is 5-10\% higher priced than its competitors like Supreme. 


\section{Macrothink}

- Low Above the Line (ATL) advertising; for the last 3-4 years the company has reduced its spending on ATL activities.

- Low presence in Retail

The opportunities for Nilkamal are:

- Company should look for new avenues in distribution channels in line with up-coming opportunities.

- There are certain gaps in eastern India market and have lots of potential due for exploitation. Thereby the company should re-look at sales \& marketing operation in this part of the country.

Major threat for Nilkamal is Supreme; it is a financially strong company and can take Nilkamal head on.

\section{Recommendations for Future Marketing Strategy}

In order to be a dominant player in furniture industry, Nilkamal is suggested the following marketing strategies:

\section{Target Kid's furniture kit}

With the revolution of media, even the kid's today are becoming brand conscious. There has been a substantial increase in the number of brands like weekender kids etc. which are targeted at the kid's. All the major brands are launching a range of products which are mainly targeted at the kid's. Special kid's products and a retail store for the same would be needed in this case.

a) Kid's furniture set to include:

-Chair's

-Dining table

$\bullet$ Racks

-Bed's

-Bunker bed's

-Rocking Chair's

$\bullet$ Stools

b) Advertise the products as being designed with respect to safety by avoiding sharp edges. This can become a trend or a fad, as kids tend to follow suit of other kids. If this is advertised and promoted well, this can be one of the better selling products of Nilkamal.

c) The furniture set can be customized to suit the kid's tastes. For eg: With cartoon shaped designs or stickers, paints etc. This would appeal to the kids. 


\section{Macrothink}

2. Retail outlets for plastic furniture

-A retail chain for Plastic Furniture can be opened in major cities.

- One stop destination for all the furniture needs of a consumer

-Complete range of furniture available in all shapes, sizes, designs and colours

\section{Resale Market}

One reason why consumers don't prefer Plastic furniture is that it is difficult to dispose. The disposal norms are relatively stringent in developed countries. With the norms getting more stringent in the country, there can be a problem of disposal in the future. To counter this,

-A resale store can be opened at major cities in the country where the sales of plastic furniture are high.

-This resale store would cater to the consumers who want to sell off their used plastic furniture as well as those consumers who want to buy used furniture.

- The company can gain out of charging a fixed percentage charge over the price.

-A win-win situation for both Nilkamal as well as the consumers.

4. Venture into wood-plastic composite furniture

- One of the niche areas in furniture today

-Would include the benefits of both wooden and plastic furniture

-Will be light weight, cheap, durable which are characteristics of plastic furniture

-Will be stylish, wooden finish and exude class which are characteristics of wooden furniture.

\section{References}

Chattopadhyay, P., \& Jain, R. (2017). Recent Stipulation of Organized Retailing in India: A Literature Review. Global Journal of Marketing Management and Research, 7(1), 5-21.

Chen, H., Yu, Z., \& Ye, B. (2016). Exploration and Application of Hui-Style Architecture in Modern Furniture Design. Furniture, 6, 010.

Dawes, J. (2018). The Ansoff Matrix: A Legendary Tool, But with Two Logical Problems. https://dx.doi.org/10.2139/ssrn.3130530

Gedenk, K., Neslin, S. A., \& Ailawadi, K. L. (2010). Sales promotion. In Retailing in the 21st Century (pp. 393-407). Springer Berlin Heidelberg.

Jaworski, B. J. (2018). Commentary: Advancing marketing strategy in the marketing discipline and beyond. Journal of Marketing Management, 34(1-2), 63-70. https://doi.org/10.1080/0267257X.2017.1398770

Olson, E. M., Slater, S. F., Hult, G. T. M., \& Olson, K. M. (2018). The application of human 


\section{Macrothink

resource management policies within the marketing organization: The impact on business and marketing strategy implementation. Industrial Marketing Management. https://doi.org/10.1016/j.indmarman.2018.01.029

Singh, D., \& Balivada, P. K. (2017). Indian retailing perspective: challenges and opportunities. South Asian Journal of Marketing \& Management Research, 7(4), 66-80. http://dx.doi.org/10.5958/2249-877X.2017.00023.6

Voorveld, H. A., van Noort, G., Muntinga, D. G., \& Bronner, F. (2018). Engagement with Social Media and Social Media Advertising: The Differentiating Role of Platform Type. Journal of Advertising, 47(1), 38-54. https://doi.org/10.1080/00913367.2017.1405754

Wiley, K. (2017). From Your Phone To Your Home: An Augmented Reality Brand Experience for High-End Furniture.

\section{Copyright Disclaimer}

Copyright for this article is retained by the author(s), with first publication rights granted to the journal.

This is an open-access article distributed under the terms and conditions of the Creative Commons Attribution license (http://creativecommons.org/licenses/by/4.0/). 